Session Number: 1465

\title{
Mathematical Induction: The Basis Step of Verification and Validation in a Modeling and Simulation Course
}

\author{
Kathleen M. Kaplan, D.Sc., Legand Burge, Ph.D., Moses Garuba, Ph.D., \\ Lt Col John J. Kaplan (Ph.D., J.D.) USAF
}

Howard University/USAF

\begin{abstract}
Most Engineering Schools offer a course in Modeling and Simulation. This is an important area of exploration as indicated by many driving forces of current research including the U.S.

Department of Defense Modeling and Simulation Office, the Air Force Agency for Modeling and Simulation, and the U.S. Navy Air Defense Threat Simulation \& Validation Office. Thus, the study of Modeling and Simulation (M\&S) should be included in any engineering program. Unfortunately, the basic foundations of the area are not being taught; university courses in M\&S have shifted from the introduction and use of formal techniques to application of software packages, such as Arena. While the use of application software is a favorable teaching tool, the programs do not allow students to fully understand and appreciate the underlying concepts of $\mathrm{M} \& S$. For example, a large part of $M \& S$ is in Verification and Validation (V\&V). There are four V\&V categories of techniques for simulation models: Informal, Static, Dynamic, and Formal, yet students who are exposed solely to application software programs may not be knowledgeable about $\mathrm{V} \& \mathrm{~V}$, let alone know the names of these four categories. A popular textbook regarding a widely-used M\&S program does not discuss $V \& V$ until its seventh chapter, wherein it has a four page discussion of verification; later, in its thirteenth chapter, three pages are dedicated to both $V \& V$. Out of a six hundred sixty eight page $M \& S$ book, only seven pages are dedicated to $\mathrm{V} \& \mathrm{~V}$. This does not coincide with the demand for the knowledge of $\mathrm{V} \& \mathrm{~V}$ as evident by specific Department of Defense offices dedicated to V\&V. M\&S educators must bring back to the classroom the use of $\mathrm{V} \& \mathrm{~V}$ techniques for simulation models, starting at ground zero: the formal technique using mathematical induction.

This paper will discuss the $\mathrm{M} \& \mathrm{~S}, \mathrm{~V} \& \mathrm{~V}$, and the current educational trend in $\mathrm{M} \& \mathrm{~S}$, specifically in the areas of $\mathrm{V} \& \mathrm{~V}$, and provide ways to incorporate the use of mathematical induction, an area of the four technique categories of $\mathrm{V} \& \mathrm{~V}$, into the teaching of $\mathrm{M} \& \mathrm{~S}$. In combining both a computer application program and $\mathrm{V} \& \mathrm{~V}$ techniques, the student will be able to fully appreciate the connection of mathematics and engineering, required in all ABET accredited programs.
\end{abstract}

"Proceedings of the 2004 American Society for Engineering Education Annual Conference \& Exposition Copyright $\mathbb{C} 2004$, American Society for Engineering Education” 


\section{Introduction}

Modeling and Simulation $(M \& S)$ is an important course in many engineering disciplines. It is usually found in the upper levels of undergraduate engineering education, an indication that underlying engineering principles must be utilized to fully understand and apply its content. $M \& S$ is a very diverse subject and incorporates many different areas of expertise, yet most undergraduate engineering students are only being exposed to application software. There is no need to have any underlying expertise, merely the means to point-and-click.

Obviously, an application-only approach does not require any mathematical skills. This is unfortunate since the engineering student will not be able to make the necessary connection of mathematics to M\&S. Also, ABET requirements are not fulfilled by the point-and-click method of teaching M\&S. Therefore, other approaches must be the standard for M\&S.

Discussions of $\mathrm{M} \& \mathrm{~S}, \mathrm{~V} \& \mathrm{~V}$, mathematical induction, and the current educational trend in $\mathrm{M} \& \mathrm{~S}$ follow. Also, the paper includes suggested of ways to incorporate the use of mathematical induction into the teaching of M\&S, and a specific example. The first topic discussed is the most important: the relevance of incorporating mathematical induction into an M\&S course.

\section{Relevance}

Before embarking on a discussion of educating engineering students in Verification and Validation $(V \& V)$ in Modeling and Simulation $(M \& S)$ courses using mathematical induction, references to its importance must be specified. These references include the importance in research as well as ABET accreditation.

\subsection{Importance in Research}

$\mathrm{M} \& \mathrm{~S}$ is an important area in today's world and economy. This is evident by the relevance given to the subject by the United States Department of Defense (DoD). DoD has at least four offices dedicated to M\&S: (1) The Air Force Agency for Modeling and Simulation (AFAMS) [9]; (2) The U.S. Department of Defense Modeling and Simulation Office [11]; (3) The U.S. Army Model and Simulation Office (AMSO), and; (4) The U.S. Navy Air Defense Threat Simulation \& Validation Office [12]. Note that $V \& V$ is especially important in all of these offices as the Department of Defense has specific procedures for accreditation of modeling and simulation [5].

\subsection{Importance in ABET Accreditation}

Educating engineering students with respect to mathematical induction in $V \& V$ within $M \& S$ is in accordance with the guidelines specified by the Accreditation Board Engineering Technology (ABET). In the ABET 2004-2005 criteria for "Accrediting Engineering Programs," the "Program Criteria for Electrical, Computer, and Similarly Named Engineering Programs" section states in "Criterion 3. Program Outcomes and Assessment" specifically that "Engineering programs must demonstrate that their graduates have: (a) an ability to apply knowledge of mathematics, science, and engineering; (b) an ability to design and conduct experiments, as well 
as to analyze and interpret data; (c) an ability to design a system, component, or process to meet desired needs; ... (e) an ability to identify, formulate, and solve engineering problems; ... (k) an ability to use the techniques, skills, and modern engineering tools necessary for engineering practice." And most specific disciplines require a "proficiency in mathematics" [1].

Therefore, introducing the M\&S engineering student to mathematical induction techniques in $\mathrm{V} \& \mathrm{~V}$ is important in two ways: it gives the student information that is vital in today's world and it is in accordance with ABET.

\section{Modeling and Simulation (M\&S)}

Modeling and Simulation (M\&S) allows engineers to further study the effects of a real-world event. Modeling encompasses researching the event and formalizing a representation; simulation uses this representation to create an implementation that spans time over the given event. In this way, a complex system can be modeled and different scenarios can be simulated without affecting the actual system. By using modeling and simulation, important data can be obtained that would be a basis for making managerial or technical decisions [12]. Typical examples of modeling and simulation are aircraft flight simulators or electronic circuit simulators [14].

\section{Verification and Validation ( $\mathrm{E} \& \mathrm{~V})$}

A large part of M\&S is in Verification and Validation $(\mathrm{V} \& \mathrm{~V})$. Verification answers the question: Does the model or simulation accurately represent the conceptual description and specification? Validation answers the question: Does the model or simulation accurately represent the real-world with respect to its intended use? [11] These V\&V questions can be answered by established techniques.

There are four V\&V categories for the techniques for simulation models: Informal, Static, Dynamic, and Formal [4]. Each of these categories has a set of techniques applicable to V\&V. Within the Informal group there are eight techniques, including the famous Turing Test. Under Static, there are ten main techniques, with three of these having between two and four subsets. Dynamic Techniques is the most populous category with twenty-seven techniques and five of these having between three and eight subsets. The Formal category has eight techniques, one of these being Induction.

All of these categories, Informal, Static, Dynamic, and Formal, are virtually absent from the education of engineering students who are exposed only to application software programs. To demonstrate the disproportional teaching of mathematical induction, a popular textbook regarding a widely-used $M \& S$ program has a little more than one percent ( 7 out of 686) of pages dedicated to the V\&V technique [6]. This type of behavior does not indicate the serious demand for the knowledge of V\&V as evident by specific Department of Defense offices dedicated to $\mathrm{V} \& \mathrm{~V}$. The extremely low percentage is a red-flag for M\&S educators, and indicates that all university $M \& S$ courses should incorporate $V \& V$ techniques for simulation models.

"Proceedings of the 2004 American Society for Engineering Education Annual Conference \& Exposition Copyright (C2004, American Society for Engineering Education” 


\section{Mathematical Induction}

Induction is a V\&V technique found within the Formal category. Engineering students should be introduced to this technique in all M\&S courses.

\subsection{History of Mathematical Induction}

In 370 BC, Plato's Parmenides may have contained the first inductive proof ever [2]. Later, in 1575, the first known description of mathematical induction was published in Francesco Maurolico's Arithmeticorum Libri Duo of 1575 [17]. Thus, the area of mathematical induction is not new, but it may be new to many engineering students!

\subsection{Mathematical Induction in a Nutshell}

Mathematical induction is a way to prove statements for all integers. These statements usually include equations, but may be compounded. In its simplest form, a statement may be given with a variable integer $n$; proof of the validity of the statement for all values of $n$ can be obtained through mathematical induction.

There are two steps in mathematical induction: the basis step and the inductive step. The basis step is the most trivial case. For the statement using $n$, this would be when $n$ equals zero, or the lowest integer value possible. The inductive step is a more difficult process. It includes assuming that the statement is true for a value and using this information to prove for the next highest value. For the statement using $n$, this would include assuming that the statement is true for $n-1$ and proving the statement for $n$.

For example, suppose the proof of the following statement is needed for all $n \geq 1$ :

$$
\sum_{i=1}^{n} i=\frac{n(n+1)}{2} \text {. }
$$

Using mathematical induction, this answer can be found below. The intermediate statements and explanations are given. Note that a question mark, "?," is used for unknown relationship until proven. 
Prove by induction on $n \geq 1$ that:

$$
\sum_{i=1}^{n} i=\frac{n(n+1)}{2}
$$

Basis Step. Prove for $\mathrm{n}=1$ :

\begin{tabular}{|l|l|}
\hline$\sum_{i=1}^{n} i ? \frac{n(n+1)}{2}$ & Problem statement \\
\hline$\sum_{i=1}^{1} i ? \frac{1(1+1)}{2}$ & Substituted 1 for every occurrence of $\mathrm{n}$ \\
\hline $1 ? \frac{1(2)}{2}$ & Summation executed, simplified. \\
\hline $1=1$, proven true for $\mathrm{n}=1$. & Basis Step proven true for $\mathrm{n}=1$. \\
\hline
\end{tabular}

Inductive Step: Assume true for $n-1$, prove for $n$.

In this case, the following is assumed true:

$$
\sum_{i=1}^{n-1} i=\frac{(n-1)((n-1)+1)}{2}=\frac{(n-1) n}{2} .
$$

\begin{tabular}{|l|l|}
\hline$\sum_{i=1}^{n} i ? \frac{n(n+1)}{2}$ & Problem statement \\
\hline$\sum_{i=1}^{n-1} i+\sum_{i=n}^{n} i ? \frac{n(n+1)}{2}$ & Expansion using summation \\
\hline$\sum_{i=1}^{n-1} i+n ? \frac{n(n+1)}{2}$ & Simplify \\
\hline$\frac{(n-1) n}{2}+n ? \frac{n(n+1)}{2}$ & Substituted assumption \\
\hline$\frac{(n-1) n+2 n}{2} ? \frac{n(n+1)}{2}$ & Combined left hand side \\
\hline$\frac{n^{2}-n+2 n}{2} ? \frac{n(n+1)}{2}$ & Expanded parentheses \\
\hline$\frac{n^{2}+n}{2} ? \frac{n(n+1)}{2}$ & Simplified \\
\hline$\frac{n(n+1)}{2}=\frac{n(n+1)}{2}$, proven true for $n$. & Inductive Step proven true for $n$. \\
\hline
\end{tabular}




\section{Verification and Validation and Mathematical Induction}

Mathematical Induction can be used at any time during the $V \& V$ process [16]. Note that due to its finiteness, a model and simulation concludes after a finite number of steps. Mathematical induction should be used early in the V\&V process, but should not stop there [4]. By mathematical induction, the completeness of the entire system can be proven [16].

To use mathematical induction to prove model correctness, the following steps can be conducted [7][8]:

1. Identify, for all variables, input-to-output relations,

2. Convert these relations into statements and place one at the beginning and end of each model execution path,

3. Prove for each path that, if the beginning statement true and all statements along the path are executed, then the assertion at the end of the path is true.

4. If all paths in simulation are proven by induction, the model is proved to be correct.

\section{Introducing Mathematical Induction to M\&S Engineering Students}

In M\&S, students should be utilizing probability distributions, such as the binomial, exponential, and beta, to name three. Proving probability distributions with mathematical induction is a natural introduction to the Formal V\&V technique.

For example, let the engineering student prove by induction on $n$ that the binomial distribution:

$$
b(k ; n, p)=\left(\begin{array}{l}
n \\
k
\end{array}\right) p^{k} q^{n-k}, k=0 \ldots n,
$$

is true. The binomial distribution, $b$, gives the probability of $k$ successes in $n$ trials, where $p$ is the probability of success and $q$ is the probability of failure. Note that the equation for the binomial coefficient is:

$$
\left(\begin{array}{l}
n \\
k
\end{array}\right)=\frac{n !}{k !(n-k) !}
$$

for $k \in N, n \in N, k \leq n$, and is defined to be the number of ways of choosing $k$ things from $n$ without replacement. Also, it should be noted by the engineering student that the following identity may be useful:

$$
\left(\begin{array}{l}
n \\
k
\end{array}\right)=\left(\begin{array}{c}
n-1 \\
k
\end{array}\right)+\left(\begin{array}{l}
n-1 \\
k-1
\end{array}\right) \text {. }
$$

A simpler version of the problem follows. 
Prove by induction on $n$ that:

$$
(p+q)^{n}=\sum_{k=0}^{n}\left(\begin{array}{l}
n \\
k
\end{array}\right) p^{k} q^{n-k}
$$

\section{Answer:}

Basis Step: Prove for $\mathrm{n}=0$.

\begin{tabular}{|l|l|}
\hline$(p+q)^{n} ? \sum_{k=0}^{n}\left(\begin{array}{l}n \\
k\end{array}\right) p^{k} q^{n-k}$ & Problem Statement \\
\hline$(p+q)^{0} ? \sum_{k=0}^{0}\left(\begin{array}{l}0 \\
k\end{array}\right) p^{k} q^{0-k}$ & Substituted 0 for every occurrence of $\mathrm{n}$ \\
\hline $1 ? \frac{0 !}{0 !(0-0) !} \cdot p^{0} q^{0}$ & Binomial coefficient \\
\hline $1=1$, proven true for $n=0$ & Basis Step proven true for $n=0$. \\
\hline
\end{tabular}


Inductive Step: Assume true for $n-1$, prove for $n$.

\begin{tabular}{|c|c|}
\hline$(p+q)^{n} ? \sum_{k=0}^{n}\left(\begin{array}{l}n \\
k\end{array}\right) p^{k} q^{n-k}$ & Problem statement \\
\hline$(p+q)^{n} ? \sum_{k=0}^{0}\left(\begin{array}{l}n \\
k\end{array}\right) p^{m} q^{n-k}+\sum_{k=1}^{n-1}\left(\begin{array}{l}n \\
k\end{array}\right) p^{k} q^{n-k}+\sum_{k=n}^{n}\left(\begin{array}{l}n \\
k\end{array}\right) p^{k} q^{n-k}$ & $\begin{array}{l}\text { Expansion using property of } \\
\text { summation }\end{array}$ \\
\hline$(p+q)^{n} ? q^{n}+\sum_{k=1}^{n-1}\left(\left(\begin{array}{c}n-1 \\
k\end{array}\right)+\left(\begin{array}{c}n-1 \\
k-1\end{array}\right)\right) p^{k} q^{n-k}+p^{n}$ & $\begin{array}{l}\text { First term: Trivial } \\
\text { Second term: Used identity } \\
\text { Third term: Trivial }\end{array}$ \\
\hline$(p+q)^{n} ? q^{n}+\sum_{k=1}^{n-1}\left(\begin{array}{c}n-1 \\
k\end{array}\right) \cdot p^{k} q^{n-k}+\sum_{k=1}^{n-1}\left(\begin{array}{l}n-1 \\
k-1\end{array}\right) \cdot p^{k} q^{n-k}+p^{n}$ & Property of summation \\
\hline $\begin{aligned}(p+q)^{n} ? q^{n} & +\sum_{k=1}^{n-1}\left(\begin{array}{c}n-1 \\
k\end{array}\right) \cdot p^{k} q^{n-1-k}+\sum_{k=0}^{n-1}\left(\begin{array}{c}n-1 \\
k\end{array}\right) \cdot p^{k+1} q^{n-1-k} \\
& -\sum_{k=n-1}^{n-1}\left(\begin{array}{c}n-1 \\
k\end{array}\right) \cdot p^{k+1} q^{n-1-k}+p^{n}\end{aligned}$ & $\begin{array}{l}\text { Changed index }- \text { instead of } \\
\text { starting at } \mathrm{k}=1 \text {, now start at } \\
\mathrm{k}=0 \text {, but subtract that term } \\
\text { too }\end{array}$ \\
\hline $\begin{array}{c}(p+q)^{n} ? q^{n}+\sum_{k=1}^{n-1}\left(\begin{array}{c}n-1 \\
k\end{array}\right) \cdot p^{k} q^{n-1-k} \cdot q+\sum_{k=0}^{n-1}\left(\begin{array}{c}n-1 \\
k\end{array}\right) \cdot p^{k} q^{n-1-k} \cdot p \\
-p^{n}+p^{n}\end{array}$ & $\begin{array}{l}\text { Factored out } b \text { and } a \text {, and } \\
\text { trivial summation }\end{array}$ \\
\hline$(p+q)^{n} ? q^{n}+q \cdot \sum_{k=1}^{n-1}\left(\begin{array}{c}n-1 \\
k\end{array}\right) \cdot p^{k} q^{n-1-k}+p \cdot \sum_{k=0}^{n-1}\left(\begin{array}{c}n-1 \\
k\end{array}\right) \cdot p^{m} q^{n-1-k}$ & $\begin{array}{l}\text { Factored out } b \text { and a from } \\
\text { sums }\end{array}$ \\
\hline $\begin{array}{l}(p+q)^{n} ? q^{n}+q \cdot \sum_{k=0}^{n-1}\left(\begin{array}{c}n-1 \\
k\end{array}\right) \cdot p^{k} q^{n-1-k} \\
-q \cdot \sum_{k=0}^{0}\left(\begin{array}{c}n-1 \\
k\end{array}\right) \cdot p^{k} q^{n-1-k}+p \cdot(p+q)^{n-1}\end{array}$ & $\begin{array}{l}\text { Changed index of first sum } \\
\text { (minus off again), and trivial } \\
\text { sum }\end{array}$ \\
\hline$(p+q)^{n} ? q^{n}+q \cdot(p+q)^{n-1}-q \cdot q^{n-1}+p \cdot(p+q)^{n-1}$ & Substituted assumption \\
\hline$(p+q)^{n} ? q \cdot(p+q)^{n-1}+p \cdot(p+q)^{n-1}$ & Simplified \\
\hline$(p+q)^{n} ?(p+q)(p+q)^{n-1}$ & Grouped \\
\hline$(p+q)^{n}=(p+q)^{n}$, proven true for $n$ & $\begin{array}{l}\text { Induction Step proven true } \\
\text { for } n\end{array}$ \\
\hline
\end{tabular}

Note that this is just one example of introducing mathematical induction into an M\&S course.

\section{Current State of M\&S Courses}

Using a popular textbook as an indication of $\mathrm{V} \& \mathrm{~V}$ material introduced into $\mathrm{M} \& \mathrm{~S}$ courses, it can be stated that the basic foundations of the area are not being taught. A popular textbook is Simulation with Arena [6], as evident by the Arena website statement, "Over 500 educational 
institutions are using Arena today!" [3]. This widely-used M\&S textbook, with Arena program included, has a little more than one percent ( 7 out of 686) of pages dedicated to the V\&V technique [6]. Unfortunately, this shows that the 500 educational institutions using this text have probably forgone the introduction and use of formal techniques and have instead adopted using this application software package.

It must be noted though that the authors' institution, Howard University (HU), is one of the 500 indicated that use Arena for its M\&S course, yet our students are taught the different categories of $\mathrm{V} \& \mathrm{~V}$ and are given problems in mathematical induction. HU is fully aware of the advantages of this point-and-click technology, but it is not willing to base its entire M\&S course upon the application technology in this software program.

Upon contacting ten other universities, none were found that introduce any Formal technique into their classrooms, nor do any discuss the four categories. This is an oversight that must be corrected, otherwise universities will be producing not engineers of technology, but users of technology.

\section{Conclusion}

This paper has shown that Modeling and Simulation (M\&S) is an important topic, as evident by the Department of Defense's many offices. It has also been shown that an important part of $\mathrm{M} \& \mathrm{~S}$ is Verification and Validation $(\mathrm{V} \& \mathrm{~V})$, and one of $\mathrm{V} \& \mathrm{~V}$ 's Formal techniques is mathematical induction. Discussions of $\mathrm{M} \& \mathrm{~S}, \mathrm{~V} \& \mathrm{~V}$, the relevance of $\mathrm{V} \& \mathrm{~V}$ and mathematical induction to engineering studies with respect to ABET have also been presented. Ways to incorporate mathematical induction into an M\&S course have been given as well.

It has also been presented that in current $M \& S$ courses, many undergraduate engineering students are only being exposed to application software. No relation is given to any underlying expertise, merely the means to point-and-click.

$\mathrm{M} \& \mathrm{~S}$ educators must bring back to the classroom the use of $\mathrm{V} \& \mathrm{~V}$ techniques for simulation models, starting at ground zero: the formal technique using mathematical induction. This paper has given one way to make this connection and introduction. The current application software must be combined with information regarding the underlying principles necessary to understand M\&S; otherwise students are not becoming engineers of technology, merely users of technology. 


\section{References}

[1] Accreditation Board Engineering Technology (ABET), "Criteria for Accrediting Engineering Programs, Effective for Evaluations During the 2004-2005 Cycle," approved Nov. 1, 2003, http://www.abet.org/images/Criteria/E001\%200405\%20EAC\%20Criteria\%2011-20-03.pdf, accessed Jan. 2004.

[2] Acerbi, F. "Plato: Parmenides 149a7-c3. A proof by Complete Induction?" Archive for History of Exact Sciences. Volume 55, Issue 1, pp. 57-76, 2000.

[3] Arena website, http://www.arenasimulation.com, accessed Jan. 2004.

[4] Balci, Osman, "Verification, Validation and Accreditation of Simulation Models," Proceedings of the 1997 Winter Simulation Conference, 1997.

[5] DoD Instruction 5000.61, "DoD Modeling and Simulation (M\&S) Verification, Validation, Accreditation (VVA)," April 29, 1996

[6] Kelton, W. David, Randall P. Sadowski, David T. Sturrock, Simulation with Arena, $3^{\text {rd }}$ ed., McGraw-Hill, 2004.

[7] Manna, Z., Ness, S., and J. Vuillemin, "Inductive methods for proving properties of programs," Communications of the ACM, 16 (8), pp. 491-502, 1973.

[8] Reynolds, C., and R.T. Yeh, "Induction as the basis for program verification," IEEE Transactions on Software Engineering, SE-2 (4), pp. 244-252, 1976.

[9] United States Air Force Agency for Modeling and Simulation (AFAMS), http://www.msiac.dmso.mil/mscalendar/default.asp?fctn=orgdetails\&orgid=147, accessed Jan. 2004.

[10] United States Army Model and Simulation Office (AMSO), http://www.amso.army.mil/main.htm, accessed Jan. 2004.

[11] United States Department of Defense, Defense Modeling and Simulation Office, https://www.dmso.mil/public/, accessed Jan. 2004.

[12] United States Navy, Navy Air Defense Threat Simulation \& Validation Office, DoD 5000.61 DoD Modeling and Simulation (M\&S) Verification, Validation, and Accreditation (VV\&A), http://www.ailtso.com/simval/Documents/5000.61/dod5000.61.htm, accessed October 17, 2003.

[13] United States Navy Air Weapons Center, Training Systems Division Glossary, M\&S Educational Training Tool (MSETT), April 28, 1994. 
[14] On-line computing dictionary, Infostreet, http://www.instantweb.com, accessed 12/8/03.

[15] V\&V Technique Taxonomy, 61 DoD Modeling and Simulation (M\&S) Verification, Validation, and Accreditation (VV\&A), Recommended Practices Guide, 2001

[16] Wentworth, James A., Rodger Knaus, and Hamid Aougab, Verification, Validation and Evaluation of Expert Systems, An FHWA Handbook, vol.1, 1st Ed. (Version 1.2), http://www.tfhrc.gov/advanc/vve/cover.htm, accessed Jan. 2004.

[17] Yale College, Introduction to the History of Mathematics: Certainty, Uncertainty and the Infinite, Seminar Paper Presentation, Fall 2003, http://info.med.yale.edu/therarad/summers/abstract.htm, accessed Jan. 2004.

\section{Biographical Information}

KATHLEEN M. KAPLAN, D.Sc.

Dr. Kaplan is an Assistant Professor in the Department of Systems \& Computer Science at Howard University. She is also a Registered Patent Agent licensed to practice before the United States Patent and Trademark Office. She can be reached atkkaplan@howard.edu.

LEGAND BURGE, Ph.D.

Dr. Burge is an Assistant Professor in the Department of Systems \& Computer Science at Howard University. He can be reached at blegand@scs.howard.edu.

MOSES GARUBA, Ph.D.

Dr. Garuba is an Assistant Professor in the Department of Systems \& Computer Science at Howard University. He can be reached at gmos66@yahoo.com.

JOHN J. KAPLAN, Ph.D., J.D.

Dr. Kaplan is a Lieutenant Colonel ( $\mathrm{Lt} \mathrm{Col}$ ) in the United States Air Force and a Patent Attorney. Lt Col Kaplan is currently the Commander of the $694^{\text {th }}$ Support Squadron. He can be reached at 694spts.cc@ft-meade.af.mil.

"Proceedings of the 2004 American Society for Engineering Education Annual Conference \& Exposition

Copyright (C2004, American Society for Engineering Education”, 